\title{
Hypothesis
}

\section{Using Complementary and Alternative Medicines to Target the Host Response during Severe Influenza}

\author{
Lisa M. Alleva ${ }^{1}$, Charles Cai $^{2}$ and lan A. Clark ${ }^{1}$ \\ ${ }^{1}$ Research School of Biology, The Australian National University, Canberra and ${ }^{2}$ Chinese Treatment Centre, \\ Suite 4 Professional Centre, Turner, Australia
}

\begin{abstract}
It is now accepted that an overwhelming inflammatory response is the cause of human deaths from avian $\mathrm{H} 5 \mathrm{~N} 1$ influenza infection. With this in mind we sought to examine the literature for examples of complementary and alternative medicines that reduce inflammation, and to place the results of this search in the context of our own work in a mouse model of influenza disease, using a pharmaceutical agent with anti-inflammatory properties. Two Chinese herbs, Angelica sinensis (Dang Gui) and Salvia miltiorrhiza (Danshen), have been recently shown to protect mice during lethal experimental sepsis via inhibition of the novel inflammatory cytokine High Mobility Group Box 1 protein (HMGB1). Biochanin A, a ligand of the peroxisome proliferator activated receptors (PPAR) alpha and gamma and the active isoflavone in Trifolium pratense (red clover), has anti-inflammatory properties, and thus could be used as an influenza treatment. This is of great interest since we have recently shown that gemfibrozil, a drug used to treat hyperlipidemia in humans and a synthetic ligand of PPAR alpha, significantly reduces the mortality associated with influenza infections in mice. The inflammation-modulating abilities of these natural agents should be considered in light of what is now known about the mechanisms of fatal influenza, and tested as potential candidates for influenza treatments in their own right, or as adjunct treatments to antivirals.
\end{abstract}

Keywords: High Mobility Group Box 1 protein - inflammatory response - red clover traditional Chinese medicine

\section{Introduction}

It is now generally accepted that the infectious agent in isolation does not cause the illness and fatal outcome seen in acute systemic infectious diseases. Instead, the pathogen induces host cells to generate excessive amounts of pro-inflammatory cytokines, the prototypic example being tumor necrosis factor (TNF), that alter organ function and host metabolism, thus generating the disease we observe $(1,2)$. This general concept, originally proposed to describe the severe disease caused by malaria infection (3), then sepsis (4) and influenza (5), has taken root in the

For reprints and all correspondence: Lisa Alleva, Research School of Biology, Building 41 Linnaeus Way, The Australian National University, Canberra ACT 0200, Australia. Tel: +61-2-61254941;

Fax: +61-2-61250313; E-mail: lisa.alleva@anu.edu.au mainstream, and is now often referred to as the 'cytokine storm' (6).

Influenza researchers have embraced the cytokine storm mechanism as an explanation for the fatal human disease caused by avian H5N1 influenza (7-9). Likewise, the pandemic influenza outbreak of 1918 is likely to have induced an overwhelming and fatal cytokine response in humans, as mice and monkeys infected with a reconstructed 1918 influenza virus exhibited a dysregulated immune response and hypercytokinemia, which leads to death (10-12). The inevitable 3-6-month delay in vaccine availability in the event of a pandemic (13) means that treatments to prevent death (but not necessarily infection) are a necessity. Existing problems with antiviral drugs (stockpiles not big enough to treat populations, drugs need to be taken prophylactically or very soon after 
infection, resistant virus strains have emerged) further necessitate investigation into other treatments (14). Targeting the detrimental host response generated by particularly pathogenic strains of influenza virus would allow disease severity to be reduced to the point where people will be sick, but will not die as a result of infection. We see agents with an ability to damp inflammatory cytokine release [be they natural or pharmaceutical (15)] as ideal candidates for influenza disease treatments, particularly during the period while a new vaccine is being generated, and as useful adjunct treatments to antivirals. As has been suggested for statins (16), using agents that are in use in the human population for the treatment of other conditions means that the safety of such agents is already established, as is the optimal human dose range.

\section{A New Pharmaceutical Treatment for Severe Influenza?}

We have found that the pharmaceutical agent, gemfibrozil, already used in the human population to treat hyperlipidemia, protects a significant proportion of mice infected with influenza virus (H2N2) from developing a fatal disease (17). Gemfibrozil belongs to the fibrate class of drugs, which, like statins, are used to lower blood lipid levels, although fibrates differ in their mechanism of action. Gemfibrozil is a synthetic ligand for the peroxisome proliferator activated receptor (PPAR) alpha. This nuclear receptor controls lipid homeostasis, with fatty acids and eicosanoids as endogenous ligands $(18,19)$. We chose gemfibrozil for its known ability to reduce release of inflammatory cytokines, including TNF, interleukin (IL)-6 and interferon- $\gamma$ (IFN- $\gamma$ ), as well its ability to inhibit the nuclear translocation of the transcription factor nuclear factor $\kappa-\mathrm{B}(\mathrm{NF}-\kappa \mathrm{B})$ (20-22), and hypothesized that these drug side-effects might be useful in ameliorating influenza disease, as has already been suggested (23). We have found that the protective ability of gemfibrozil during influenza infections is likely to be a fibrate class effect, since fenofibrate also reduces the mortality of influenza virus-infected mice (unpublished data). Gemfibrozil lowers serum IL-6 levels in mice infected with influenza virus (unpublished data) but its effects on other aspects of the host immune response are not yet known, and remain the subject of our further study.

It is important to note that the use of fibrates and statins in the human population for lipid-lowering has not, to our knowledge, enhanced susceptibility to viral disease. This is probably due to the fact that the innate antiviral response to infection, for example expression of the antiviral protein, $\mathrm{Mx}$, is regulated by type I interferons and not by TNF or IL-1 (24). While TNF has been reported to exert direct antiviral effects against influenza virus in vitro (25) its antiviral effects in vivo are less clear. Administration of neutralizing anti-TNF antibodies during the course of influenza in mice did not increase viral titers, and the infection still resolved (26). Furthermore, the course of infection of H5N1 influenza virus was not worsened in mice genetically unable to produce TNF (27). It is therefore unlikely that agents that interfere with expression of pro-inflammatory cytokines such as TNF will enhance susceptibility to influenza, but this remains to be experimentally tested.

The strategy of selecting agents with anti-inflammatory properties need not only apply to pharmaceutical agents. There are already precedents in the literature for the use of natural agents to treat severe infections such as influenza. Ginseng and Salviae (28) have been trialed for their abilities to improve influenza vaccination outcomes with good results, and may also modulate cytokines to reduce immunopathology during influenza infections. Researchers working during the SARS outbreak used complementary medicines to treat a small number of SARS patients with good results, and suggested that these treatments might be useful in treating cases of avian influenza $(29,30)$. A recent review of the antiviral and immunomodulatory effects of compounds isolated from plants and traditional Chinese medicines describes a Chinese study in which FM1 influenza virus-infected mice were given the traditional Chinese medicine Yiqi Qingwen Jiedu Heji (31). Researchers found that this treatment reduced expression of the cytokines TNF, IL- 6 and IFN- $\gamma$ in the lungs of FM1 influenza-infected mice, all of which are implicated in inflammation, and increased levels of the anti-inflammatory cytokine IL-10, the combined effect being a shortened course of influenza disease (32). Glycyrrhizin, an active component of liquorice roots, when given to mice from one day before infection with influenza virus (H2N2), protected all treated mice from fatality while all control mice died (33). What is most interesting about this result is that glycyrrhizin binds to, and inactivates, the novel pro-inflammatory mediator High Mobility Group Box 1 protein (HMGB1) (34), which is elevated in the serum of sepsis patients who succumbed to infection (35).

With these non-pharmaceutical precedents in mind, we searched the literature for examples of complementary and alternative medicines used to treat conditions other than influenza that are characterized by increased pro-inflammatory cytokine levels, for their potential to mitigate the host response during severe influenza.

\section{Looking Towards Other Conditions for Clues}

\section{Sepsis}

Experimental models for sepsis provide an excellent avenue for understanding pathophysiology and 
mechanisms of disease during severe inflammatory states. Because sepsis is characterized by a prolonged inflammatory state that, if untreated, results in death (36), it is comparable to the cytokine storm that ensues in H5N1 influenza infections in people. Any agents that have proven to be of benefit in sepsis models should be considered as candidates for influenza treatments, and we have found several examples in the literature of complementary medicines that do this.

The low molecular weight fraction of an aqueous extract of the Chinese herb Angelica sinensis (Dang Gui) is dose-dependently protective during lethal experimental sepsis and endotoxemia (37). Ninety percent of mice were saved during lethal endotoxemia (when only $30 \%$ of controls survived) when the extract was given daily, and $70 \%$ of mice were saved during lethal sepsis (when only $25 \%$ of controls survived) when the extract was given daily. What is most impressive is that in the sepsis model, the repeated administration of the extract was not begun until $24 \mathrm{~h}$ after the onset of sepsis, when some animals had already died. The authors also showed that this late administration significantly reduced serum levels of HMGB1, and attributed the rescue of mice in part to the attenuation of systemic HMGB1 accumulation by the herbal extract. This effect on HMGB1 is important as HMGB1 is the only high mobility group protein with an additional extracellular function, a cytokine-like activity $(38,39)$. It is this function that many researchers have become interested in since the first demonstration in 1999 of the presence of high levels of HMGB1 in the serum of mice and human patients with sepsis (35). What is most unusual about HMGB1 is that its secretion continues for an uncommonly long time, with peak levels detected in cell cultures $18 \mathrm{~h}$ after stimulation (35). This is in contrast to TNF secretion, for example, which peaks $90 \mathrm{~min}$ after the initial stimulus. In turn, once released into the circulation HMGB1 generates a further wave of inflammatory cytokine production (40) through its receptors, the receptor for advanced glycation endproducts [RAGE; $(41,42)$ ], and toll-like receptors 2 and 4 (43). This ability to amplify and prolong inflammation is consistent with observations in sepsis where both HMGB1 and other inflammatory cytokines are persistently elevated $(44,45)$.

Recently, the same group of researchers showed that the aqueous extract of another Chinese herb, Salvia miltiorrhiza (Danshen), traditionally used to treat cardiovascular disorders, was also protective against lethal endotoxemia and sepsis by decreasing HMGB1 levels in vivo (46). As for the Dang Gui extract, the Danshen extract was administered $24 \mathrm{~h}$ after the onset of sepsis yet still rescued mice. As a potential anti-influenza treatment Danshen may have a double-pronged attack, as it also possesses anti-viral activity $(47,48)$.

Artemisinin, a Chinese herb traditionally used as an anti-malarial drug, has been shown to possess potent anti-inflammatory effects via inhibition of $\mathrm{NF}-\kappa \mathrm{B}(49)$. It, too, protects against lethal endotoxemia (50) thus warranting its consideration as a potential influenza treatment. Chloroquine possesses antiviral (51) and anti-inflammatory activities (52) and has already been suggested as a potential treatment for pandemic influenza (23).

Ginseng is another herb with potent anti-inflammatory effects. An extract from Korean red ginseng (Panax ginseng, C.A. Meyer) significantly protected mice in experimental sepsis by decreasing TNF, IL-1, IL-6 and IFN- $\gamma$ production via inhibition of NF- $\kappa \mathrm{B}$ activation (53-55). It is likely that Korean ginseng will also reduce HMGB1 levels, because cytokines under the control of $\mathrm{NF}-\kappa \mathrm{B}$, such as TNF and IFN- $\gamma$, induce HMGB1 (56). Green tea (Camellia sinensis) reduces endotoxin-induced release of HMGB1 and is also proposed to possess the ability to decrease mortality from sepsis if taken regularly (57).

\section{Pancreatitis}

Chronic pancreatitis is characterized by increased serum levels of pro-inflammatory cytokines (58). Acute pancreatitis attacks are often followed by multiple organ failure and death, due to the overproduction of inflammatory cytokines (59) and like H5N1 influenza, the 'cytokine storm' mechanism has been used to describe this syndrome (60). Serum levels of HMGB1 are known to be elevated during acute pancreatitis (61). Danshen (S. miltiorrhiza), described above as being protective during experimental sepsis, also protects against acute pancreatitis by reducing levels of reactive oxygen species (62), downstream by-products of inflammation. Its use in two syndromes that are characterized by an altered host response, leading to multiple organ failure and death, should make it a priority for influenza researchers interested in examining the effect of immunomodulatory treatments on the course of influenza disease.

\section{Menopause}

Pro-inflammatory cytokines are increased during menopause with ensuing pathologies including osteoporosis and atherosclerosis (63). Red clover (Trifolium pratense) isoflavone extracts are widely used for relieving postmenopausal symptoms in women. Biochanin A is the major isoflavone present in red clover, and activates both PPAR alpha and gamma receptors in vitro (64). Gemfibrozil, the synthetic PPAR alpha ligand that increases survival of mice during severe murine influenza (17), possesses anti-inflammatory side effects including inhibition of NF- $\mathrm{BB}$ activity; this transcription factor is essential for the transcription of pro-inflammatory genes (21). Similarly, biochanin A has been recently shown to decrease production of the pro-inflammatory cytokine 
TNF, as well as its downstream mediators nitric oxide and superoxide (65). The fact that biochanin A activates both PPAR alpha and gamma would be an advantage in treating severe influenza, as the PPAR gamma agonist pioglitazone was recently shown to reduce the mortality associated with PR8 influenza in mice (66). It is possible that combining PPAR alpha and gamma activation in one treatment, using biochanin A, may prove more effective in curbing influenza-related mortality than activation of either PPAR receptor alone.

The above examples of complementary medicines, used in seemingly disparate syndromes to treat essentially the same thing - pathological cytokine excess-should provide researchers working in the influenza field with a solid starting point for in vivo studies in animal models of the disease.

\section{A Traditional Chinese Formula Could Also Protect Against Severe Influenza}

Prescribed mixtures of Chinese herbs are given to patients with influenza. A common formula contains Jin Yin Hua (honeysuckle flower), Lian Qiao (forsythia fruit), Bo $\mathrm{He}$ (field mint), Jing Jie (schizonepeta), Jie Geng (root of balloon flower), Gan Cao (licorice root), Dang Gui (A. sinensis root), Dang Shen (Codonopsis root), Chai $\mathrm{Hu}$ (thorowax), Qianghuo (Notopterygium root) and Sheng Jiang (fresh ginger rhizome). Intriguingly, nine of these 11 herbs have been shown to possess antiinflammatory properties. A. sinensis is dose-dependently protective during lethal experimental sepsis and endotoxemia (37) via its ability to limit release of HMGB1, as has already been discussed. There are many examples of Jie Geng (root of balloon flower), reducing both production of pro-inflammatory cytokines and proinflammatory mediators (such as reactive oxygen species and nitric oxide), with these effects likely to be mediated through suppression of activation of NF-кB [e.g. see ref. (67)]. Sheng Jiang (fresh ginger rhizome), Gan Cao (licorice root) and Lian Qiao (forsythia fruit) also reduce levels of inflammatory cytokines via suppression of NF-kB induction (e.g. see refs (68-70). Thus it seems that a mixture of herbs, as traditionally prescribed, is likely to have profound effects on the inflammatory cytokine balance, warranting further investigation of the mixture itself in vitro and in vivo.

\section{Proposed Methodology}

HMGB1 has a growing literature on its involvement in the pathogenesis of severe inflammatory states. Large amounts of HMGB1 have been detected in the serum of sepsis patients who succumbed to infection (35). Similarly, during falciparum malaria levels of HMGB1 are higher in patients who do not recover (71).
However recent observations paint a more complex picture of the significance of elevated serum HMGB1 measurements. Sepsis patients with severe organ dysfunction had the lowest serum HMGB1 levels of all sepsis patients tested (72), which probably points to a well-known sideeffect of acute infection, immunosuppression. We have shown that despite plasma levels of HMGB1 being low at the time of peak mortality in mice infected with A/Japan/305/57 influenza virus (H2N2), HMGB1 may be elevated via its passive release in the lung at this time (73). Therefore it would be important to first ascertain, using animal models of influenza, how levels of HMGB1, in the serum and/or lung, were associated with pathology and/or fatality. Our own work in this area continues, as does our focus on optimizing the way in which HMGB1 is measured for study. Figure 1 shows the likely sources and role of HMGB1 during infection with influenza virus.

Therapeutic interventions in sepsis models, such as administration of ethyl pyruvate (74), an agent that limits HMGB1 release in vitro, or administration of an anti-HMGB1 antibody (75), save a significant proportion of mice, implicating the inhibition of HMGB1 release or activity as a therapeutic target during immune pathology. As previously mentioned, glycyrrhizin protects influenza virus (H2N2)-infected mice from fatality (33) potentially via its ability to bind to, and inactivate, HMGB1 (34). Therefore it would be important to establish whether or not therapeutic intervention with any of the agents discussed here reverse the fatality of severe influenza in animal models via effects on HMGB1 and/or other aspects of the host response.

However, endogenously produced molecules that dampen the effects of HMGB1 in the circulation are also elevated during severe disease states. Thrombomodulin, which binds to HMGB1 and prevents it binding to RAGE (76) is elevated during severe malaria (77), sepsis $(78,79)$ and influenza $(80)$. Paradoxically, it is this binding of HMGB1 to thrombomodulin that also prevents activated protein $C$ generation (81) and thus its ensuing anti-inflammatory activities $(82,83)$. Thus the balance between HMGB1 and thrombomodulin in vivo is likely to be important (81) and should also be determined as part of these studies.

A second, broader strategy could be to examine the traditional Chinese medicine formula discussed here, indeed, any other traditional formulas in their entirety, for anti-inflammatory activity in vitro. Cultured mouse macrophages could be stimulated with either commercially available recombinant influenza virus $\mathrm{H} 5 \mathrm{~N} 1$ haemagglutinin (HA) or LPS to induce production of pro-inflammatory cytokines, in the presence or absence of the formula, prepared as traditionally described (simmered in boiling water for 45-60 min). Cytokine assays to profile pro- and anti-inflammatory cytokines secreted over time into the culture supernatant could 


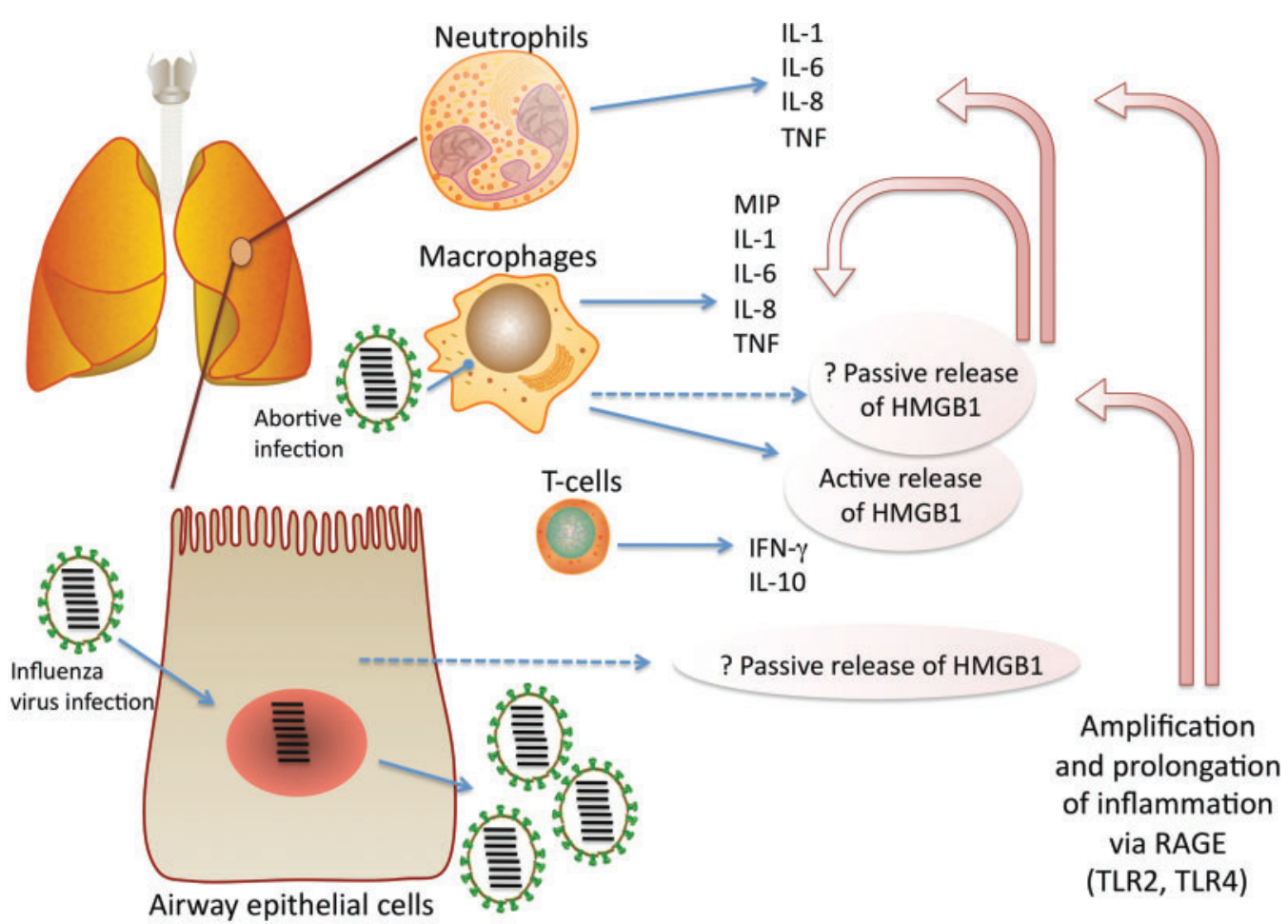

Figure 1. Amplification and prolongation of inflammation by high mobility group box 1 protein (HMGB1) during influenza. Influenza virus-infected airway epithelial cells may passively release HMGB1 [see ref. (92) as an example], while alveolar macrophages, which become infected with influenza virus (93), secrete pro-inflammatory cytokines and may also secrete HMGB1 both actively and passively. MIP is macrophage inflammatory protein. Cytokines (excluding IL-10) commonly reported to be involved in pathogenesis were compiled from (94-96). IL-10 from effector T-cells was recently shown to limit inflammation during acute influenza (97). HMGB1 up-regulates pro-inflammatory cytokine expression via its cellular receptors, the receptor for advanced glycation end products [RAGE; $(41,42,98)$ ] and to a lesser extent, toll-like receptor (TLR) 2 and 4 (43,99). RAGE expression was recently shown to be associated with influenza A virus pneumonia, accompanied by increased levels of HMGB1 in bronchoalveolar lavage fluid (100).

then be conducted, using a system such as multiplexing to examine many different cytokines in each sample (such as anti-inflammatory cytokines IL-4 and IL-10, and pro-inflammatory cytokines IL-1, IL-2, IL-6, IL-8, IL-17, IFN- $\gamma$, TNF and HMGB1). Given results which point towards levels of pro-inflammatory cytokines being reduced by treatment of the cells with the formula, the next step would be to conduct studies in mice infected with influenza virus (such as mouse-adapted PR8) and administered the formula orally, daily, adjusted according to body weight. Parameters measured in the in vivo experiments could initially include analysis of serum and lung cytokine levels, body weight and temperature, and even survival, providing researchers could interact with their institutional ethics committee to arrive at a mutually appropriate end-point for euthanasia for experiments of this nature.

Systematic reviews of the literature on clinical trials using traditional Chinese medicine in influenza patients have demonstrated the need for proper design, using randomized controlled trials and sufficiently large study groups to gain meaningful results $(84,85)$ as well as a more systematic approach to disease diagnosis (86). Thus it would be informative to take the insights gained from results in mice into the clinic. Patients hospitalized with influenza could be recruited [see ref. (87) for parameters relating to recruitment] to a randomized controlled trial to determine if treatment with a traditional Chinese medicine formula (for example, the formula previously discussed here) affected the course of disease. It would be prudent to begin treatment immediately, before laboratory confirmation of influenza virus infection. This is because symptoms are apparent at the time of increased serum cytokine levels (87). Obviously patients testing negative to influenza virus would subsequently be excluded from analysis. The decoction would be prepared in the traditional manner (simmering in boiling water for $45-60 \mathrm{~min}$ ) and administered to patients by hospital staff. The control treatment could simply be a flavored water solution that is stored in the same way as the decoction $\left(\right.$ at $4^{\circ} \mathrm{C}$ for not more than 1 week), and consumed daily in the same quantity as the decoction. Both solutions should be colored identically (with a food-grade dye, for example). It would be ideal to ensure the trial was conducted in a double-blind fashion so that neither the patient nor the staff knew which treatment was active. Previous studies have compared the incidence of influenza-like illness in healthcare workers 
using an herbal formula against those using no agent (88) but results were questioned because workers given the herbal formula knew that they were taking the 'active' treatment. While these trials recruited thousands of patients, we suggest that patient numbers could be kept relatively small in the first instance (20 patients per group) if, in addition to patients being unaware of the activity of the treatment they are given, daily blood samples are taken to measure serum levels of cytokines, as for the in vitro assays described above. One milliliter of blood would provide enough serum to analyze cytokine levels, and daily measurements on the same individual would allow for paired statistical analysis. The appropriate end-point would be convalescence, but obviously if symptoms worsened with treatment (or control) then standard interventions should immediately take place. These basic but necessary experiments could pave the way towards viable, low cost alternatives to planned influenza pandemic treatments - approximately $\$ 8$ for a fortnight's treatment (88). Figure 2 summarizes the possible inflammation-reducing effects of traditional Chinese medicines (e.g. A. sinensis, S. miltiorrhiza and glycyrrhizin), a natural agent (biochanin A), and pharmaceutical interventions (e.g. statins, fibrates), during influenza.

\section{A Note on Non-medicinal Interventions}

Direct stimulation of the vagus nerve has been shown to exert potent inflammation-reducing activities in the body (89). Transcutaneous stimulation of the vagus nerve improves survival in mice with sepsis by reducing serum levels of HMGB1 (90). Thus there is a distinct possibility that vagus nerve stimulation by acupuncture could control immune-mediated pathology, by limiting release of pro-inflammatory cytokines. The potential for using acupuncture in this way was recently reviewed (91) with the authors noting that the use of acupuncture as an adjunct therapy to conventional medical treatment for a number of chronic inflammatory and autoimmune diseases seems plausible and should be validated by confirming its cholinergicity'. Thus stimulation of the vagus nerve in patients with influenza could also represent an adjunct treatment in the management of severe influenza cases, provided it can be further investigated.

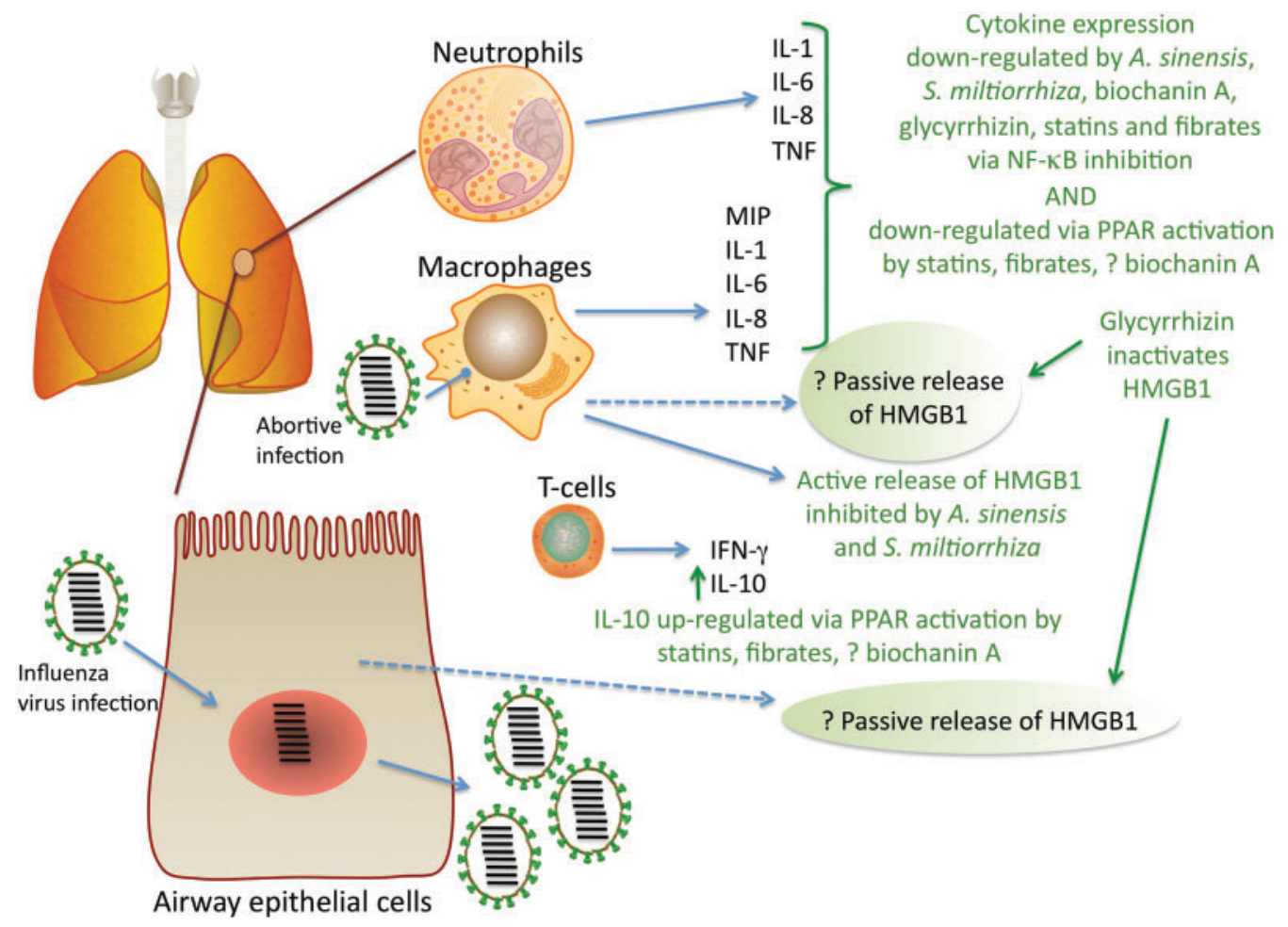

Figure 2. Potential mitigation of the action of HMGB1 and other pro-inflammatory cytokines by traditional Chinese medicines, a natural agent, and pharmaceutical drugs. The Chinese medicine glycyrrhizin, from liquorice root, binds to HMGB1 and inactivates its biological activities (34), while the Chinese herbs A. sinensis and S. miltiorrhiza reduce the release of HMGB1 $(37,46)$. Release of pro-inflammatory cytokines is reduced via inhibition of NF- $\mathrm{BB}$ activation, by glycyrrhizin (101-103), A. sinensis (104,105), and S. miltiorrhiza $(106,107)$; by the natural agent biochanin A $(65,108,109)$; and the pharmaceutical drugs statins $(110,111)$ and fibrates $(21,112,113)$. Pro-inflammatory cytokine release is reduced by activation of PPARs (21) and conversely, anti-inflammatory cytokine release is increased by their activation (114,115). PPAR alpha is activated by fibrates (21); PPAR alpha and gamma are activated by biochanin A (64); and statins upregulate PPAR alpha and gamma and show molecular signaling properties similar to fibrates (116). 


\section{Conclusion}

The example given here of an ancient Chinese medicine formula used to treat influenza containing nine (out of 11) herbs with anti-inflammatory properties provides compelling evidence that the way forward for the treatment of influenza in a pandemic should be immunomodulation. The host response is targeted, rather than the virus itself. Our observation that treatment of influenza virus-infected mice with a pharmaceutical used in humans, the lipid-lowering and immunomodulatory PPAR alpha agonist gemfibrozil, resulted in significantly decreased influenza-induced mortality, further shows that targeting the host response is a valid possibility. The natural immunomodulatory agent biochanin A from Red Clover, which is both a PPAR alpha and PPAR gamma agonist, could have similar effects to gemfibrozil on the course of influenza disease in vivo. Chinese herbs such as $A$. sinensis and $S$. miltiorrhiza which independently reduce secretion of the novel inflammatory cytokine HMGB1, and glycyrrhizin from liquorice root, which binds to HMGB1 and inactivates its activity, provide another avenue for investigation, as does the establishment of the role of HMGB1 in severe influenza. The wide availability and low economic price of these agents could make such agents an inexpensive alternative treatment, particularly in countries with large populations who will have no access to pandemic vaccines or antivirals.

\section{Acknowledgements}

Dr Alison Budd provided valuable discussion in the preliminary stages of manuscript preparation, and Dr David Fedson continues to provide input and critical discussion. The authors would like to thank the reviewers for their thoughtful comments.

\section{Funding}

National Health and Medical Research Council Australia (Grant no. 471402).

\section{References}

1. Clark IA, Alleva LM, Mills AC, Cowden WB. Pathogenesis of malaria and clinically similar conditions. Clin Microbiol Rev 2004; 17:509-39.

2. Clark IA, Budd AC, Alleva LM, Cowden WB. Human malarial disease: a consequence of inflammatory cytokine release. Malar J 2006;5:85.

3. Clark IA, Virelizier JL, Carswell EA, Wood PR. Possible importance of macrophage-derived mediators in acute malaria. Infect Immun 1981;32:1058-66.

4. Clark IA. Suggested importance of monokines in pathophysiology of endotoxin shock and malaria. Klin Wochenschr 1982;60:756-8.

5. Clark IA, Cowden WB. Is TNF a key to acute infectious illness? Today's Life Science 1989;1:26-9.

6. Clark IA. The advent of the cytokine storm. Immunol Cell Biol 2007;85:271-3.
7. Cheung CY, Poon LL, Lau AS, Luk W, Lau YL, Shortridge KF, et al. Induction of proinflammatory cytokines in human macrophages by influenza A (H5N1) viruses: a mechanism for the unusual severity of human disease? Lancet 2002;360:1831-7.

8. de Jong MD, Simmons CP, Thanh TT, Hien VM, Smith GJ, Chau TN, et al. Fatal outcome of human influenza A (H5N1) is associated with high viral load and hypercytokinemia. Nat Med 2006; $12: 1203-7$

9. To KF, Chan PK, Chan KF, Lee WK, Lam WY, Wong KF, et al. Pathology of fatal human infection associated with avian influenza A H5N1 virus. J Med Virol 2001;63:242-6.

10. Hampton T. Virulence of 1918 influenza virus linked to inflammatory innate immune response. JAMA 2007;297:580.

11. Kash JC, Tumpey TM, Proll SC, Carter V, Perwitasari O, Thomas MJ, et al. Genomic analysis of increased host immune and cell death responses induced by 1918 influenza virus. Nature 2006;443:578-81.

12. Kobasa D, Jones SM, Shinya K, Kash JC, Copps J, Ebihara H, et al. Aberrant innate immune response in lethal infection of macaques with the 1918 influenza virus. Nature 2007;445:319-23.

13. Booy R, Brown LE, Grohmann GS, Macintyre CR. Pandemic vaccines: promises and pitfalls. Med J Aust 2006;185:S62-5.

14. Hayden FG, Pavia AT. Antiviral management of seasonal and pandemic influenza. J Infect Dis 2006;1:S119-26.

15. Rainsford KD. Influenza ("Bird Flu"), inflammation and antiinflammatory/analgesic drugs. Inflammopharmacology 2006;14:2-9.

16. Fedson DS. Pandemic influenza: a potential role for statins in treatment and prophylaxis. Clin Infect Dis 2006;43:199-205.

17. Budd A, Alleva L, Alsharifi M, Koskinen A, Smythe V, Mullbacher A, et al. Increased survival after gemfibrozil treatment of severe mouse influenza. Antimicrob Agents Chemother 2007;51: 2965-8.

18. Forman BM, Chen J, Evans RM. Hypolipidemic drugs, polyunsaturated fatty acids, and eicosanoids are ligands for peroxisome proliferator-activated receptors alpha and delta. Proc Natl Acad Sci USA 1997;94:4312-7.

19. Issemann I, Prince RA, Tugwood JD, Green S. The peroxisome proliferator-activated receptor:retinoid $\mathrm{X}$ receptor heterodimer is activated by fatty acids and fibrate hypolipidaemic drugs. $J \mathrm{Mol}$ Endocrinol 1993;11:37-47.

20. Zhao SP, Ye HJ, Zhou HN, Nie S, Li QZ. Gemfibrozil reduces release of tumor necrosis factor-alpha in peripheral blood mononuclear cells from healthy subjects and patients with coronary heart disease. Clin Chim Acta 2003;332:61-7.

21. Chinetti G, Fruchart JC, Staels B. Peroxisome proliferator-activated receptors (PPARs): nuclear receptors at the crossroads between lipid metabolism and inflammation. Inflamm Res 2000;49:497-505.

22. Cunard R, Ricote M, DiCampli D, Archer DC, Kahn DA, Glass CK, et al. Regulation of cytokine expression by ligands of peroxisome proliferator activated receptors. J Immunol 2002;168: 2795-802.

23. Fedson DS. Confronting an influenza pandemic with inexpensive generic agents: can it be done? Lancet Infect Dis 2008;8:571-6.

24. Simon A, Fah J, Haller O, Staeheli P. Interferon-regulated $\mathrm{Mx}$ genes are not responsive to IL-1, TNF, and other cytokines. J Virol 1991;65:968-71.

25. Van Campen H. Influenza A virus replication is inhibited by tumor necrosis factor-alpha in vitro. Arch Virol 1994;136:439-46.

26. Peper RL, Van Campen H. Tumor necrosis factor as a mediator of inflammation in influenza A viral pneumonia. Microb Pathog 1995; 19:175-83.

27. Salomon R, Hoffmann E, Webster RG. Inhibition of the cytokine response does not protect against lethal $\mathrm{H} 5 \mathrm{~N} 1$ influenza infection. Proc Natl Acad Sci USA 2007;104:12479-81.

28. Quan FS, Compans RW, Cho YK, Kang SM. Ginseng and Salviae herbs play a role as immune activators and modulate immune responses during influenza virus infection. Vaccine 2007;25:272-82.

29. Hsu CH, Hwang KC, Chao CL, Chang SG, Ho MS, Chou P. Can herbal medicine assist against avian flu? Learning from the experience of using supplementary treatment with Chinese medicine on SARS or SARS-like infectious disease in 2003. J Altern Complement Med 2006;12:505-6.

30. Hsu CH, Hwang KC, Chao CL, Chang SG, Ker CC, Chien LC, et al. The lesson of supplementary treatment with Chinese medicine 
on severe laboratory-confirmed SARS patients. Am J Chin Med 2006;34:927-35.

31. Wang X, Jia W, Zhao A. Anti-influenza agents from plants and traditional Chinese medicine. Phytother Res 2006;20:335-41.

32. Wang CX, Gao GX, Wei SC, Xu HR. The dynamic effect of yiqi qingwen jiedu heji on the protein expressions of cytokine IFN- $\gamma$, TNF-alpha, IL-10 and IL-6 in the lungs of mice infected by IV FM1. Zhongguo Zhong Yao Za Zhi 2005;30:541-4.

33. Utsunomiya T, Kobayashi M, Pollard RB, Suzuki F. Glycyrrhizin, an active component of licorice roots, reduces morbidity and mortality of mice infected with lethal doses of influenza virus. Antimicrob Agents Chemother 1997;41:551-6.

34. Mollica L, De Marchis F, Spitaleri A, Dallacosta C, Pennacchini D, Zamai M, et al. Glycyrrhizin binds to high-mobility group box 1 protein and inhibits its cytokine activities. Chem Biol 2007;14: 431-41.

35. Wang HC, Bloom $\mathrm{O}$, Zhang $\mathrm{MH}$, Vishnubhakat JM, Ombrellino M, Che JT, et al. HMG-1 as a late mediator of endotoxin lethality in mice. Science 1999;285:248-51.

36. Cohen J. The immunopathogenesis of sepsis. Nature 2002;420: $885-91$

37. Wang H, Li W, Li J, Rendon Mitchell B, Ochani M, Ashok M, et al. The aqueous extract of a popular herbal nutrient supplement, Angelica sinensis, protects mice against lethal endotoxemia and sepsis. J Nutr 2006;136:360-5.

38. Czura CJ, Wang H, Tracey KJ. Dual roles for HMGB1: DNA binding and cytokine. J Endotoxin Res 2001;7:315-21.

39. Yang H, Wang HC, Tracey KJ. HMG-1 rediscovered as a cytokine. Shock 2001;15:247-53.

40. Andersson U, Wang H, Palmblad K, Aveberger AC, Bloom O, Erlandsson Harris $\mathrm{H}$, et al. High mobility group 1 protein (HMG-1) stimulates proinflammatory cytokine synthesis in human monocytes. J Exp Med 2000;192:565-70.

41. Chao JC, Wan XS, Engelsberg BN, Rothblum LI, Billings PC. The receptor for advanced glycation end products (RAGE) is a cellular binding site for amphoterin. Mediation of neurite outgrowth and co-expression of rage and amphoterin in the developing nervous system. Biochim Biophys Acta 1996;7:213-9.

42. Kokkola R, Andersson A, Mullins G, Ostberg T, Treutiger CJ, Arnold B, et al. RAGE is the major receptor for the proinflammatory activity of HMGB1 in rodent macrophages. Scand J Immunol 2005;61:1-9.

43. Park JS, Svetkauskaite D, He Q, Kim JY, Strassheim D, Ishizaka A, et al. Involvement of toll-like receptors 2 and 4 in cellular activation by high mobility group box 1 protein. $J$ Biol Chem 2004:279:7370-7.

44. Meduri GU, Headley S, Kohler G, Stentz F, Tolley E, Umberger R, et al. Persistent elevation of inflammatory cytokines predicts a poor outcome in ARDS. Plasma IL-1 beta and IL-6 levels are consistent and efficient predictors of outcome over time. Chest 1995;107: 1062-73.

45. Sunden Cullberg J, Norrby Teglund A, Rouhiainen A, Rauvala H, Herman G, Tracey KJ, et al. Persistent elevation of high mobility group box-1 protein (HMGB1) in patients with severe sepsis and septic shock. Crit Care Med 2005;33:564-73.

46. Li W, Li J, Ashok M, Wu R, Chen D, Yang L, et al. A cardiovascular drug rescues mice from lethal sepsis by selectively attenuating a late-acting proinflammatory mediator, high mobility group box 1 . $J$ Immunol 2007;178:3856-64.

47. Wu BW, Pan TL, Leu YL, Chang YK, Tai PJ, Lin KH, et al. Antiviral effects of Salvia miltiorrhiza (Danshen) against enterovirus 71. Am J Chin Med 2007;35:153-68.

48. Zhou Z, Zhang Y, Ding XR, Chen SH, Yang J, Wang XJ, et al. Protocatechuic aldehyde inhibits hepatitis B virus replication both in vitro and in vivo. Antiviral Res 2007:74:59-64

49. Aldieri E, Atragene D, Bergandi L, Riganti C, Costamagna C, Bosia A, et al. Artemisinin inhibits inducible nitric oxide synthase and nuclear factor NF-kB activation. FEBS Lett 2003; 552:141-4.

50. Wang J, Zhou H, Zheng J, Cheng J, Liu W, Ding G, et al. The antimalarial artemisinin synergizes with antibiotics to protect against lethal live Escherichia coli challenge by decreasing proinflammatory cytokine release. Antimicrob Agents Chemother $2006 ; 50: 2420-7$
51. Yoshimura A, Kuroda K, Kawasaki K, Yamashina S, Maeda T, Ohnishi S. Infectious cell entry mechanism of influenza virus. J Virol 1982;43:284-93.

52. Ertel W, Morrison MH, Ayala A, Chaudry IH. Chloroquine attenuates hemorrhagic shock-induced suppression of Kupffer cell antigen presentation and major histocompatibility complex class II antigen expression through blockade of tumor necrosis factor and prostaglandin release. Blood 1991;78:1781-8.

53. Ahn JY, Choi IS, Shim JY, Yun EK, Yun YS, Jeong G, et al. The immunomodulator ginsan induces resistance to experimental sepsis by inhibiting Toll-like receptor-mediated inflammatory signals. Eur I Immunol 2006;36:37-45.

54. Ahn JY, Song JY, Yun YS, Jeong G, Choi IS. Protection of Staphylococcus aureus-infected septic mice by suppression of early acute inflammation and enhanced antimicrobial activity by ginsan. FEMS Immunol Med Microbiol 2006;46:187-97.

55. Lim DS, Bae KG, Jung IS, Kim CH, Yun YS, Song JY. Anti-septicaemic effect of polysaccharide from Panax ginseng by macrophage activation. $J$ Infect 2002;45:32-8.

56. Rendon Mitchell B, Ochani M, Li J, Han J, Wang H, Yang H, et al. IFN- $\gamma$ Induces High Mobility Group Box 1 protein release partly through a TNF-dependent mechanism. J Immunol 2003;170: $3890-7$.

57. Chen X, Li W, Wang H. More tea for septic patients? - green tea may reduce endotoxin-induced release of high mobility group box 1 and other pro-inflammatory cytokines. Med Hypotheses 2006;66: 660-3.

58. Talukdar R, Saikia N, Singal DK, Tandon R. Chronic pancreatitis: evolving paradigms. Pancreatology 2006;6:440-9.

59. Bhatia M, Brady M, Shokuhi S, Christmas S, Neoptolemos JP, Slavin J. Inflammatory mediators in acute pancreatitis. $J$ Pathol 2000:190:117-25.

60. Makhija R, Kingsnorth AN. Cytokine storm in acute pancreatitis. J Hepatobiliary Pancreat Surg 2002;9:401-10.

61. Yasuda T, Ueda T, Takeyama Y, Shinzeki M, Sawa H, Nakajima T, et al. Significant increase of serum high-mobility group box chromosomal protein 1 levels in patients with severe acute pancreatitis. Pancreas 2006;33:359-63.

62. Zhang XP, Li ZJ, Liu DR. Progress in research into the mechanism of Radix salviae miltiorrhizae in treatment of acute pancreatitis. Hepatobiliary Pancreat Dis Int 2006:5:501-4.

63. Pfeilschifter J, Koditz R, Pfohl M, Schatz H. Changes in proinflammatory cytokine activity after menopause. Endocr Rev 2002;23:90119.

64. Shen P, Liu MH, Ng TY, Chan YH, Yong EL. Differential effects of isoflavones, from Astragalus membranaceus and Pueraria thomsonii, on the activation of PPAR $\alpha, \operatorname{PPAR} \gamma$, and adipocyte differentiation in vitro. $J$ Nutr 2006;136:899-905.

65. Chen HQ, Jin ZY, Li GH. Biochanin A protects dopaminergic neurons against lipopolysaccharide-induced damage through inhibition of microglia activation and proinflammatory factors generation. Neurosci Lett 2007:29:29.

66. Aldridge JR Jr, Moseley CE, Boltz DA, Negovetich NJ, Reynolds C, Franks J, et al. TNF/iNOS-producing dendritic cells are the necessary evil of lethal influenza virus infection. Proc Natl Acad Sci USA 2009;106:5306-11.

67. Ahn KS, Noh EJ, Zhao HL, Jung SH, Kang SS, Kim YS. Inhibition of inducible nitric oxide synthase and cyclooxygenase II by Platycodon grandiflorum saponins via suppression of nuclear factor-кB activation in RAW 264.7 cells. Life Sci 2005;76: 2315-28.

68. Kim JK, Oh SM, Kwon HS, Oh YS, Lim SS, Shin HK. Antiinflammatory effect of roasted licorice extracts on lipopolysaccharide-induced inflammatory responses in murine macrophages. Biochem Biophys Res Commun 2006;345:1215-23, Epub 2006 May 1215

69. Kwon HM, Choi YJ, Choi JS, Kang SW, Bae JY, Kang IJ, et al. Blockade of cytokine-induced endothelial cell adhesion molecule expression by licorice isoliquiritigenin through NF- $\mathrm{KB}$ signal disruption. Exp Biol Med (Maywood) 2007:232:235-45.

70. Surh YJ, Lee JY, Choi KJ, Ko SR. Effects of selected ginsenosides on phorbol ester-induced expression of cyclooxygenase-2 and activation of NF-kB and ERK1/2 in mouse skin. Ann NY Acad Sci 2002;973:396-401. 
71. Alleva LM, Yang H, Tracey KJ, Clark IA. High mobility group box 1 (HMGB1) protein: possible amplification signal in the pathogenesis of falciparum malaria. Trans $R$ Soc Trop Med Hyg 2005;99:171-4.

72. Karlsson S, Pettila V, Tenhunen J, Laru-Sompa R, Hynninen M, Ruokonen E. HMGB1 as a predictor of organ dysfunction and outcome in patients with severe sepsis. Intensive Care Med 2008;34:1046-53.

73. Alleva LM, Budd AC, Clark IA. Systemic release of high mobility group box 1 protein during severe murine influenza. J Immunol 2008;181:1454-9.

74. Ulloa L, Ochani M, Yang H, Tanovic M, Halperin D, Yang R, et al. Ethyl pyruvate prevents lethality in mice with established lethal sepsis and systemic inflammation. Proc Natl Acad Sci USA 2002;99:12351-6.

75. Yang H, Ochani M, Li J, Qiang X, Tanovic M, Harris HE, et al. Reversing established sepsis with antagonists of endogenous high-mobility group box 1. Proc Natl Acad Sci USA 2004;101: 296-301.

76. Abeyama K, Stern DM, Ito Y, Kawahara K, Yoshimoto Y, Tanaka M, et al. The N-terminal domain of thrombomodulin sequesters high-mobility group-B1 protein, a novel antiinflammatory mechanism. $J$ Clin Invest 2005;115:1267-74.

77. Boehme MW, Werle E, Kommerell B, Raeth U. Serum levels of adhesion molecules and thrombomodulin as indicators of vascular injury in severe Plasmodium falciparum malaria. Clin Invest 1994:72:598-603.

78. Boldt J, Wollbruck T, Sonneborn S, Welters A, Hempelmann G. Thrombomodulin in intensive care patients. Intensive Care Med 1995;21:645-50.

79. Gando S, Kameue T, Nanzaki S, Nakanishi Y. Cytokines, soluble thrombomodulin and disseminated intravascular coagulation in patients with systemic inflammatory response syndrome. Thromb Res 1995;80:519-26.

80. Keller TT, van der Sluijs KF, de Kruif MD, Gerdes VE, Meijers JC, Florquin S, et al. Effects on coagulation and fibrinolysis induced by influenza in mice with a reduced capacity to generate activated protein $\mathrm{C}$ and a deficiency in plasminogen activator inhibitor type 1. Circ Res 2006;99:1261-9.

81. Ito T, Kawahara K, Nakamura T, Yamada S, Abeyama K, Hashiguchi $\mathrm{T}$, et al. High-mobility group box 1 protein promotes development of microvascular thrombosis in rats. $J$ Thromb Haemost 2007:5:109-16.

82. Esmon C. Do-all receptor takes on coagulation, inflammation. Nat Med 2005;11:475-7.

83. Esmon CT. Inflammation and the activated protein $\mathrm{C}$ anticoagulant pathway. Semin Thromb Hemost 2006;1:49-60.

84. Chen X, Wu T, Liu G. Chinese medicinal herbs for influenza: a systematic review. J Altern Complement Med 2006;12:171-80.

85. Chen XY, Wu TX, Liu GJ, Wang Q, Zheng J, Wei J, et al. Chinese medicinal herbs for influenza. Cochrane Database Syst Rev 2009; doi:10.1002/14651858.CD004559.pub3.

86. Chang I. Initiative for developing evidence-based standardization of traditional chinese medical therapy in the western pacific region of the World Health Organization. eCAM 2004;1:337-41.

87. Lee N, Wong CK, Chan PK, Lun SW, Lui G, Wong B, et al. Hypercytokinemia and hyperactivation of phospho-p38 mitogenactivated protein kinase in severe human influenza A virus infection. Clin Infect Dis 2007;45:723-31.

88. Lau JT, Leung PC, Wong EL, Fong C, Cheng KF, Zhang SC, et al. The use of an herbal formula by hospital care workers during the severe acute respiratory syndrome epidemic in Hong Kong to prevent severe acute respiratory syndrome transmission, relieve influenza-related symptoms, and improve quality of life: a prospective cohort study. J Altern Complement Med 2005;11: 49-55.

89. Borovikova LV, Ivanova S, Zhang M, Yang H, Botchkina GI, Watkins LR, et al. Vagus nerve stimulation attenuates the systemic inflammatory response to endotoxin. Nature 2000;405: 458-62.

90. Huston JM, Gallowitsch Puerta M, Ochani M, Ochani K, Yuan R, Rosas Ballina $\mathrm{M}$, et al. Transcutaneous vagus nerve stimulation reduces serum high mobility group box 1 levels and improves survival in murine sepsis. Crit Care Med 2007;35:2762-8.
91. Kavoussi B, Ross BE. The neuroimmune basis of antiinflammatory acupuncture. Integr Cancer Ther 2007;6:251-7.

92. Chen LC, Yeh TM, Wu HN, Lin YY, Shyu HW. Dengue virus infection induces passive release of high mobility group box 1 protein by epithelial cells. $J$ Infect 2008;56:143-50.

93. Rodgers BC, Mims CA. Influenza virus replication in human alveolar macrophages. J Med Virol 1982;9:177-84.

94. Hennet T, Ziltener HJ, Frei K, Peterhans E. A kinetic study of immune mediators in the lungs of mice infected with influenza A virus. J Immunol 1992;149:932-9.

95. Julkunen I, Melen K, Nyqvist M, Pirhonen J, Sareneva T, Matikainen S. Inflammatory responses in influenza A virus infection. Vaccine 2000;19(Suppl 1):S32-7.

96. Van Reeth K. Cytokines in the pathogenesis of influenza. Vet Microbiol 2000;74:109-16.

97. Sun J, Madan R, Karp CL, Braciale TJ. Effector T cells control lung inflammation during acute influenza virus infection by producing IL-10. Nat Med 2009;15:277-84.

98. Hori O, Brett J, Slattery T, Cao R, Zhang J, Chen JX, et al. The receptor for advanced glycation end products (RAGE) is a cellular binding site for amphoterin. Mediation of neurite outgrowth and co-expression of rage and amphoterin in the developing nervous system. J Biol Chem 1995;270:25752-61.

99. Wang H, Ward MF, Fan XG, Sama AE, Li W. Potential role of high mobility group box 1 in viral infectious diseases. Viral Immunol 2006;19:3-9.

100. van Zoelen MA, van der Sluijs KF, Achouiti A, Florquin S, Braun-Peter JM, Yang H, et al. Receptor for advanced glycation end products is detrimental during influenza A virus pneumonia. Virology 2009;391:265-73.

101. Wang JY, Guo JS, Li H, Liu SL, Zern MA. Inhibitory effect of glycyrrhizin on NF- $\mathrm{BB}$ binding activity in CCl4- plus ethanolinduced liver cirrhosis in rats. Liver 1998;18:180-5.

102. Takei H, Baba Y, Hisatsune A, Katsuki H, Miyata T, Yokomizo $\mathrm{K}$, et al. Glycyrrhizin inhibits interleukin-8 production and nuclear factor- $\kappa \mathrm{B}$ activity in lung epithelial cells, but not through glucocorticoid receptors. J Pharmacol Sci 2008;106: $460-8$.

103. Matsui S, Matsumoto H, Sonoda Y, Ando K, Aizu-Yokota E, Sato T, et al. Glycyrrhizin and related compounds down-regulate production of inflammatory chemokines IL-8 and eotaxin 1 in a human lung fibroblast cell line. Int Immunopharmacol 2004;4: $1633-44$.

104. Xie CH, Zhang MS, Zhou YF, Han G, Cao Z, Zhou FX, et al. Chinese medicine Angelica sinensis suppresses radiation-induced expression of TNF-alpha and TGF-betal in mice. Oncol Rep 2006; 15:1429-36.

105. Chao WW, Kuo YH, Li WC, Lin BF. The production of nitric oxide and prostaglandin E2 in peritoneal macrophages is inhibited by Andrographis paniculata, Angelica sinensis and Morus alba ethyl acetate fractions. J Ethnopharmacol 2009;122:68-75.

106. Jang SI, Kim HJ, Kim YJ, Jeong SI, You YO. Tanshinone IIA inhibits LPS-induced NF- $\mathrm{KB}$ activation in RAW 264.7 cells: possible involvement of the NIK-IKK, ERK1/2, p38 and JNK pathways. Eur J Pharmacol 2006;542:1-7.

107. Zhang X, Liu D, Wu D, Zhu C, Ye J, Wang K, et al. Effect of salvia miltiorrhizae on the expressions of TLR4 protein in the liver of rats with SAP or OJ. Inflammation 2009;32:151-62.

108. Lee KH, Choi EM. Biochanin A stimulates osteoblastic differentiation and inhibits hydrogen peroxide-induced production of inflammatory mediators in MC3T3-E1 cells. Biol Pharm Bull 2005;28:1948-53.

109. Kalayciyan A, Orawa H, Fimmel S, Perschel FH, Gonzalez JB, Fitzner RG, et al. Nicotine and biochanin A, but not cigarette smoke, induce anti-inflammatory effects on keratinocytes and endothelial cells in patients with Behcet's disease. $J$ Invest Dermatol 2007;127:81-9.

110. Pahan K, Sheikh FG, Namboodiri AM, Singh I. Lovastatin and phenylacetate inhibit the induction of nitric oxide synthase and cytokines in rat primary astrocytes, microglia, and macrophages. J Clin Invest 1997;100:2671-9.

111. Terblanche M, Almog Y, Rosenson RS, Smith TS, Hackam DG. Statins and sepsis: multiple modifications at multiple levels. Lancet Infect Dis 2007;7:358-68. 
112. Delerive P, De Bosscher K, Besnard S, Vanden Berghe W, Peters JM, Gonzalez FJ, et al. Peroxisome proliferatoractivated receptor alpha negatively regulates the vascular inflammatory gene response by negative cross-talk with transcription factors NF-кB and AP-1. J Biol Chem 1999;274: $32048-54$.

113. Okamoto H, Iwamoto T, Kotake S, Momohara S, Yamanaka H, Kamatani N. Inhibition of NF- $\mathrm{B}$ signaling by fenofibrate, a peroxisome proliferator-activated receptor-alpha ligand, presents a therapeutic strategy for rheumatoid arthritis. Clin Exp Rheumatol 2005;23:323-30.
114. Delerive P, Fruchart JC, Staels B. Peroxisome proliferator-activated receptors in inflammation control. J Endocrinol 2001;169:453-9.

115. Kim SR, Lee KS, Park HS, Park SJ, Min KH, Jin SM, et al. Involvement of IL-10 in peroxisome proliferator-activated receptor $\gamma$-mediated anti-inflammatory response in asthma. Mol Pharmacol 2005;68:1568-75.

116. Paumelle R, Staels B. Cross-talk between statins and PPARalpha in cardiovascular diseases: clinical evidence and basic mechanisms. Trends Cardiovasc Med 2008;18:73-8.

Received May 20, 2009; accepted August 30, 2009 


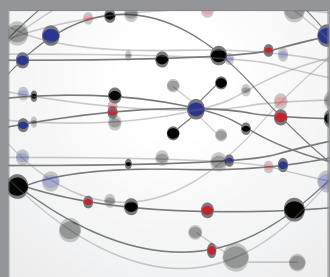

The Scientific World Journal
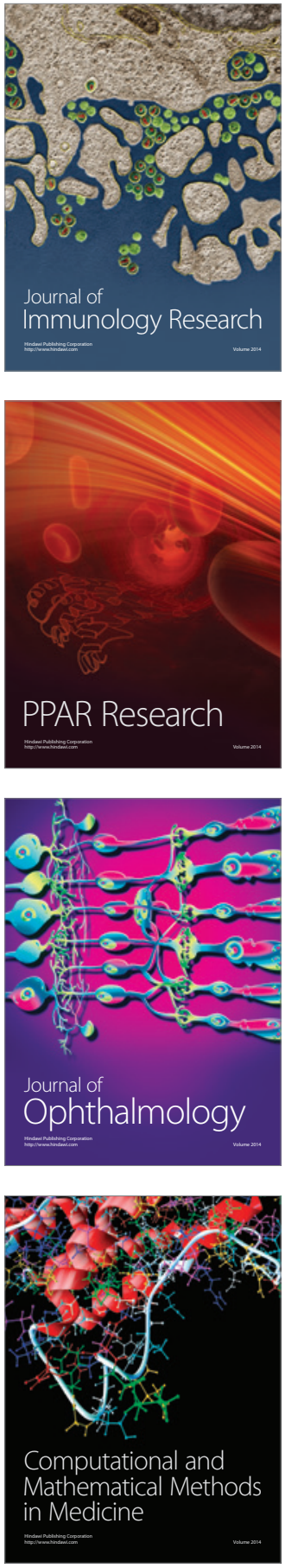

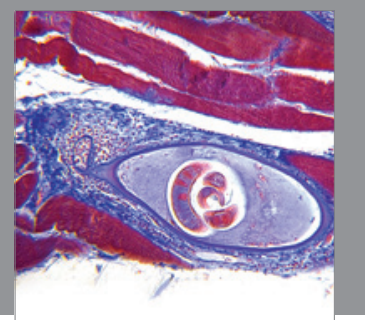

Gastroenterology

Research and Practice
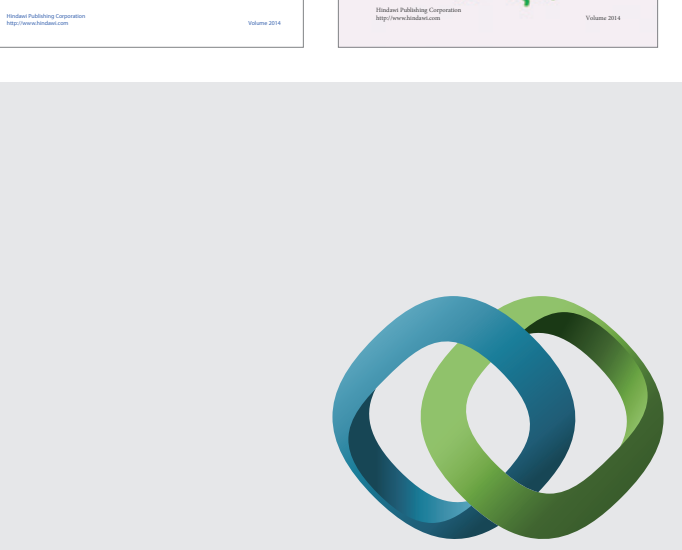

\section{Hindawi}

Submit your manuscripts at

http://www.hindawi.com
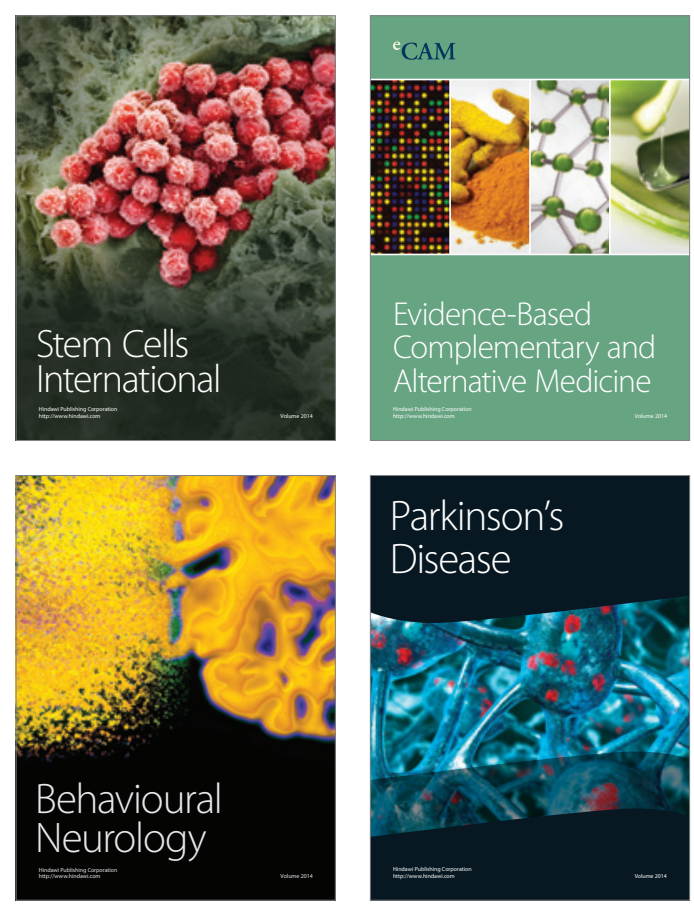

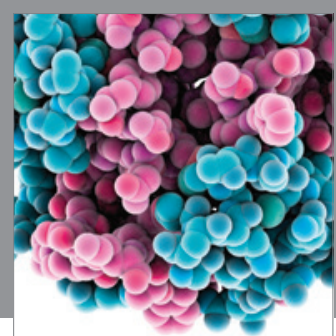

Journal of
Diabetes Research

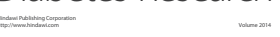

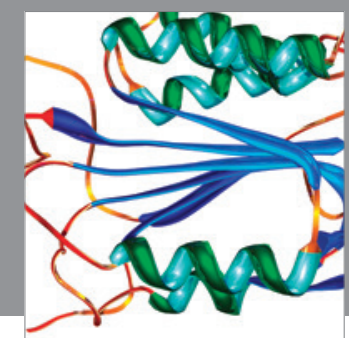

Disease Markers
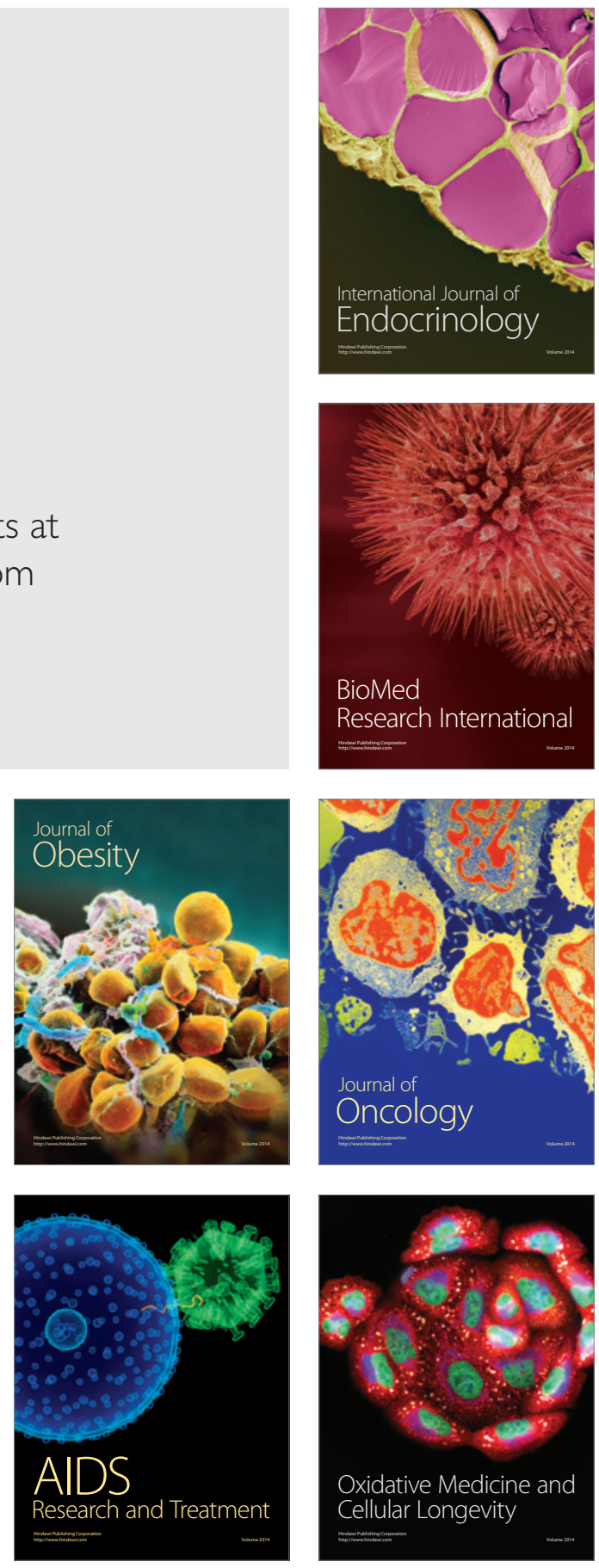